\title{
Dielectric Properties of Compatibilised EPDM/Silicone rubber Nanocomposites
}

\author{
Vijayalekshmi Vijayakumar \\ Department of Polymer Technology B.S Abdur Rahman University Chennai, India - 600048
}

\begin{abstract}
EPDM/Silicone rubber nanocomposites are prepared by incorporating various phr of organically modified montmorillonite (OMMT) nanoclay onto compatibilised and uncompatibilised EPDM/Silicone rubber blends using two roll mill. Compatibilisation of EPDM and Silicone rubber blend is achieved through insitu grafting of silane onto EPDM during mixing of rubbers. Effect of OMMT content and compatibilisation of blend system on electrical, mechanical and thermal properties of the nanocomposites are investigated. The results obtained for various properties indicate that the compatibilised EPDM/Silicone rubber nanocomposites have improved dielectric, mechanical and thermal properties compared to that of uncompatibilised blend nanocomposites. It is observed that, the addition of OMMT upto $5 \mathrm{phr}$ onto both compatibilised and uncompatibilised blends of EPDM/Silicone offers significant improvement in the above mentioned properties. Increasing content of OMMT onto the blends cause marked enhancement in thermal stability of the nanocomposties. Transmission electron micrographs shows the compatibility between EPDM and silicone rubbers in the blend and the exfoliation of OMMT layers in the matrix phase. The present work reveals that the compatibilised EPDM/ Silicone/ OMMT nanocomposite can be a better candidate for high voltage electrical insulation due to its enhanced dielectric, mechanical and themal characteristics.
\end{abstract}

KeyWords:Dielectric properties, EPDM/Silicone nanocomposites, Polymeric insulators, Rubber nanocomposites

\section{INTRODUCTION}

Polymer nanocomposites have attracted much interest in research studies over the last decades. ${ }^{1-2}$ The hybrid composites formed by nano inorganic particles exhibit drastic improvements in dielectric and mechanical properties, thermal stability, etc due to its higher surface area and enormous interfacial adhesion between nano particles and matrix material. ${ }^{3-5}$ Due to its high and reversible deformability, rubber is widely used as an important polymeric material in many applications. Since the modulus and strength of neat rubber is low, additional reinforcement is required for practical uses of rubber materials. Generally used reinforcing materials in rubber are silica, carbon blacks, fibers and silicates. Use of nano fillers to polymer materials is a promising channel for property improvement due to its higher surface area compared to the conventional fillers. ${ }^{6}$ Addition of hydrophobic layer with coupling agent is necessary to reduce the agglomeration of inorganic nano particles since they are strongly fixed by electrostatic forces to rubber. ${ }^{3,7}$ Among the inorganic fillers, montmorillonite clay is an important material to improve thermal, mechanical and electrical properties. ${ }^{8-11}$ Thermal stability of the polymer nano composites can be improved by the use of small quantity of layered silicates. The filler dispersed in the polymer matrix creates larger polymer-filler surface interaction and hence reduced oscillation amplitude of polymer chain segments and increased degradation temperature. ${ }^{8}$, ${ }^{12-13}$ To improve its compatibility with the polymer material, organically modified montmorillonites (OMMT) can be used which will replace the intergallerycations (e.g. $\mathrm{Na}^{+}$) with suitable alkyl ammonium salt. This organically modified montmorillonite can be dispersed into silicate sheets or single platelets with a higher aspect ratio by mechanical mixing. ${ }^{14}$ Silica is the most universal reinforcing filler due to the diversity in its physical characteristics and high level of performance. ${ }^{13}$ Silicone rubber is one of the most important types of high performance polymer with excellent thermal stability, low temperature toughness, electrical insulating properties, hydrophobicity and UV resistance with poor tracking resistance and increased cost. ${ }^{15-16}$ Instead, EPDM possesses excellent mechanical strength, tracking resistance with comparatively lower cost. ${ }^{17}$ Blending of polymers has gained considerable importance for achieving property improvement and economic advantages. ${ }^{13,}{ }^{17-18}$ In this study, aminopropyltriethoxysilane was used to improve the compatibility between EPDM and silicone rubber and organically modified montmorillonite(OMMT) clay used as inorganic filler. The impact of compatibilizer and OMMT 
content on mechanical, thermal and dielectric properties of EPDM/Silicone blend were studied to evaluate their potential applications for high voltage insulators.

\section{EXPERIMENTAL}

\subsection{Materials}

All the materials used for the development of nanocomposite insulators are commercially available and were used as such without further treatment. Silicone rubber (NE 5160) was supplied by Dongjue Silicone -Nanjing Co Ltd, China. EPDM (KEP 960) which contains ethylene norborene as the diene monomer was purchased from KumhoPolychem, Korea. Fumed silica (Cab O - Sil) was obtained from Cabot Corporation, Germany. OMMT used was Nanofill-5 supplied by SudChemi , Germany. Gamma aminopropyltriethoxysilane (APTES) was purchased from Degussa Evonik, Germany. Dicumyl peroxide of $40 \%$ active was used as cross linking agent.

\subsection{Preparation of EPDM/Silicone/OMMT nanocomposites}

Blends of EPDM and Silicone rubber in the presence and absence of silanecompatibiliser(APTES) was prepared by mixing equal weight percentages (1:1) of the materials in a two roll mill for about 15 minutes at room temperature. Fumed silica of required quantity was added in lot wise directly onto the blend and mixing was continued to get homogeneous mix (10-15 minutes). For the preparation of EPDM/Silicone rubber nanocomposites with varying content of OMMT, required quantities of OMMT $(0,1,3,5$ and $7 \mathrm{phr})$ was incorporated by mixing the blend in the two roll mill for about 5-10 minutes at room temperature. After getting good dispersion of filler, dicumyl peroxide (DCP) (40\% active) was added and mixed for about 5 minutes. The vulcanization of the rubber compound was carried out in a hydraulically operated press at $150^{\circ} \mathrm{C}$ for 8 minutes. The vulcanized samples were post-cured at $140^{\circ} \mathrm{C}$ for $1 \mathrm{hr}$ in an air-circulating oven. Test specimens were punched out from the compression-moulded sheets. The nanocomposites with various compositions prepared (TABLE 1) were tested for their electrical, mechanical and thermal characteristics.

\subsection{Characterization}

\subsubsection{Mechanical properties}

Tensile strength and percentage elongation at break of the nanocomposites were assessed at room temperature by using universal testing machine (UTM) at a crosshead speed of $500 \mathrm{~mm} /$ minute as per ASTM D-412. For each formulation, five specimens were tested and the average values are reported. Shore hardness was measured by using Durometer as per ASTM D 2240 and the values are expressed in A scale.

\subsubsection{Electrical properties}

Dielectric strength was tested as per IEC60243-1 (ASTM D 149) standard at $250 \mathrm{~V}$ and 50 $\mathrm{Hz}$. The diameter and thickness of the samples used were of $100 \mathrm{~mm}$ and $2 \mathrm{~mm}$ respectively. Test specimens were placed between two electrodes and the voltage was increased at a fixed rate of $2 \mathrm{kV} / \mathrm{s}$, until dielectric breakdown occurs. The voltage at which dielectric breakdown occurs was read as dielectric breakdown voltage. Dielectric strength was calculated as the ratio of dielectric breakdown voltage $(\mathrm{kV})$ to the thickness of the specimen $(\mathrm{mm})$. The volume and surface resistivity of the samples were measured as per ASTM D 257 (IEC $60093)$ standards. The voltage applied was $500 \mathrm{~V}$ (DC) for 90 seconds at room temperature. The diameter and thickness of the specimen were 100 $\mathrm{mm}$ and $3 \mathrm{~mm}$ respectively. Million meg-Ohm meter was used to measure the volume and surface resistivity. For all the above said properties the average of five values were considered. Dielectric constant and $\tan \delta$ (dissipation factor) measurements were carried out by using Weis-500 electrochemical work station (impedenceanalyser) in the frequency range of $10 \mathrm{~Hz}$ to $10^{6} \mathrm{~Hz}$ at room temperature. The specimens with $50 \mathrm{~mm}$ in diameter and $3 \mathrm{~mm}$ in thickness were used.

\subsubsection{Thermogravimetric analysis}

Thermo gravimetric analysis was carried out to analyze the thermal stability of the cured nanocomposites using a Sii TG-DTA 6500 thermal analyzer in a dry nitrogen atmosphere at a heating rate of $20^{\circ} \mathrm{C} / \mathrm{min}$.

\subsubsection{Transmission electron microscopy (TEM) Morphology of EPDM/Silicone/OMMT} nano composite was directly observed by Transmission Electron Microscopy (Model JEM 2100) at an accelerating voltage of $200 \mathrm{kV}$. Ultra thin film of nanocomposite (less than $100 \mathrm{~nm}$ ) obtained by ultra microtome cutting under cryogenic conditions was used for the morphological studies. 
Table 1Composition of EPDM/silicone/OMMT nanocomposites

\begin{tabular}{lcccccccccc}
\hline $\begin{array}{l}\text { Compositio } \\
\text { n (phr) }\end{array}$ & UCN & UCN & UCN & UCNC- & UCN & Notation & CNC- & CNC- & CNC- & CNC- \\
& C- 0 & C- 1 & C -3 & 5 & C-7 & CNC- & 1 & 3 & 5 & 7 \\
\hline EPDM & 50 & 50 & 50 & 50 & 50 & 50 & 50 & 50 & 50 & 50 \\
Silicone & 50 & 50 & 50 & 50 & 50 & 50 & 50 & 50 & 50 & 50 \\
rubber & - & - & - & - & - & 1 & 1 & 1 & 1 & 1 \\
APTES & - & & & & & & & & & \\
Fumed & 25 & 25 & 25 & 25 & 25 & 25 & 25 & 25 & 25 & 25 \\
Silica & 0 & 1 & 3 & 5 & 7 & 0 & 1 & 3 & 5 & 7 \\
OMMT & 6.25 & 6.25 & 6.25 & 6.25 & 6.25 & 6.25 & 6.25 & 6.25 & 6.25 & 6.25 \\
DCP & & & & & & & & & & \\
\hline
\end{tabular}

\section{RESULTS AND DISCUSSION}

\subsection{Mechanical properties}

The effect of OMMT on the mechanical properties of compatibilised and uncompatibilised EPDM/Silicone rubber nanocomposites was determined and the values are presented in FIGURE (1-3).It can be seen from the FIGURE (13) that tensile strength, elongation at break and hardness are higher for compatibilisednanocomposites (CNC) compared to that of uncompatibilisednano composites (UCNC). The improvements in these properties are due to the good dispersion of OMMT onto the rubber matrix. Compatibilisation of EPDM and silicone rubber by silane coupling agent improved the interfacial interaction of the component materials in the nanocomposites. The maximum value of tensile strength and elongation are observed at the filler loading of $5 \mathrm{phr}$ in both compatibilised and uncompatibilisednanocomposites. Tensile strength of EPDM/Silicone rubber nanocomposites was found to be increased to $81 \%$ by the addition of 5 phr of OMMT. In the presence of silanecompatibiliser, the increment obtained was $89 \%$. Percentage elongation at break was found to be increased up to $56 \%$ in the presence of silanecompatibiliser compared to uncompatibilisednanocomposite $(47 \%)$ at loading of $5 \mathrm{phr}$ of OMMT. The values decreased as the level of OMMT content increased beyond $5 \mathrm{phr}$ in both compatibilised and uncompatibilisednanocomposites. This may be due to the poor dispersion of OMMT at higher concentrations and hence deterioration in mechanical properties occurs. As the loading of nano filler increases, the usual trend of increasing hardness has been noticed.

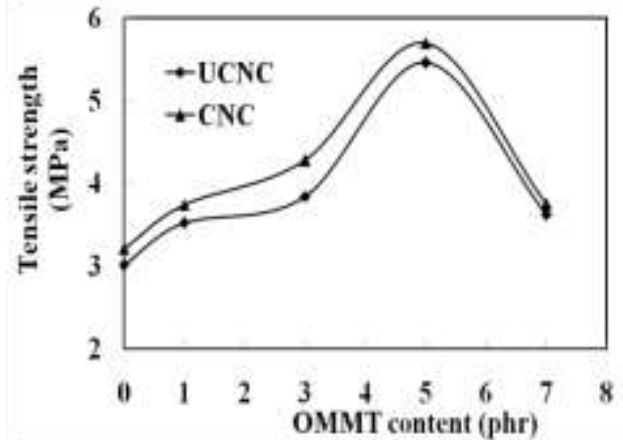

FIGURE 1. Effect of OMMT content on tensile strength of compatibilised and uncompatibilised EPDM/Silicone rubber nanocomposites

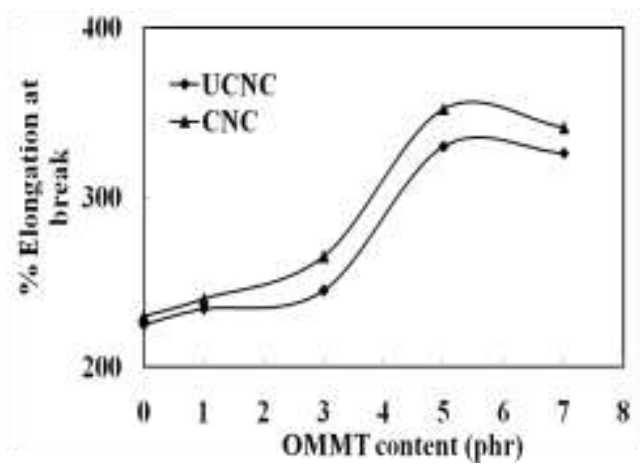

FIGURE 2. Effect of OMMT content on percentage elongation at break of compatibilised and uncompatibilised EPDM/Silicone rubber nanocomposites

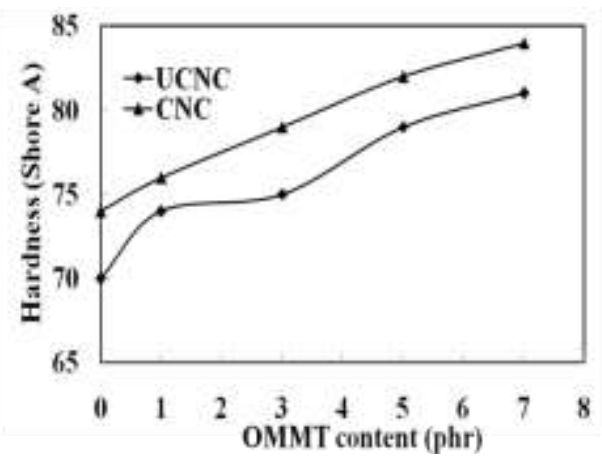


FIGURE 3. Effect of OMMT content on hardness of compatibilised and uncompatibilised EPDM/Silicone rubber nanocomposites

\subsection{Electrical characterisation}

Effect of OMMT content on electrical properties such as dielectric strength, dielectric constant, surface resistivity, volume resistivity and dissipation factor of compatibilised and uncompatibilised EPDM/Silicone rubber nanocomposites has been studied.

\subsubsection{Dielectric strength}

Dielectric strength of nanocomposites containing varying percentage of OMMT was examined and the results are shown in FIGURE 4. It indicates that, the dielectric strength of EPDM/Silicone rubber nanocomposites increased up to the filler loading of $5 \mathrm{phr}$ and then decreased with further addition. The addition of $5 \mathrm{phr}$ of OMMT onto the compatibilisednanocomposite system caused about $47 \%$ increase in dielectric strength characteristics compared to that of neat blend. The values obtained for uncompatibilisednanocomposite at loading of $5 \mathrm{phr}$ OMMT was only $32 \%$. This enhancement in dielectric property is caused by the formation of strong chemical bonds between EPDM and Silicone by the silanecompatibiliser. However on further increment of OMMT on to the system causes a decrease in dielectric strength. This may be due to the lower interspace distance between the filler particles.

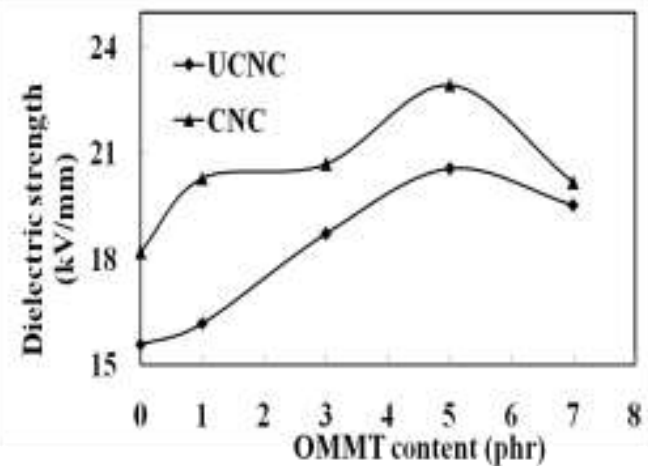

FIGURE 4.Effect of OMMT content on dielectric strength of compatibilised and uncompatibilised EPDM/Silicone rubber nanocomposites

\subsubsection{Dielectric constant}

Frequency dependent values of dielectric constant (relative permitivity) for compatibilised and uncompatibilised EPDM/Silicone rubber nanocomposites with varying OMMT content are shown in FIGURE 5 and 6.It was noticed from the FIGURE 5 that the dielectric constant of both compatibilised and uncompatibilised nanocomposites decreased with increasing frequency. FIGURE 7 shows the dielectric constant of compatibilised and uncompatibilised nanocomposites with increasing OMMT content at frequency of $1 \mathrm{MHz}$. The dielectric constant of composite without OMMT for uncompatibilised and compatibilised nanocomposites are 3.52 and 3.62 respectively. The values of dielectric constant of both compatibilised and uncompatibilised blends increases with increasing content of OMMT in the blends. The values indicate that OMMT rich compatibilised nanocomposites have higher dielectric constant. Functional group $\left[-\mathrm{Si}\left(\mathrm{C}_{2} \mathrm{H}_{5}\right)_{3}\right]$ of gamma-aminopropyl triethoxy silane is a reactive polar group. The presence of which in the compatibilised nanocomposites causes increase in dielectric constant due to electrical polarity.

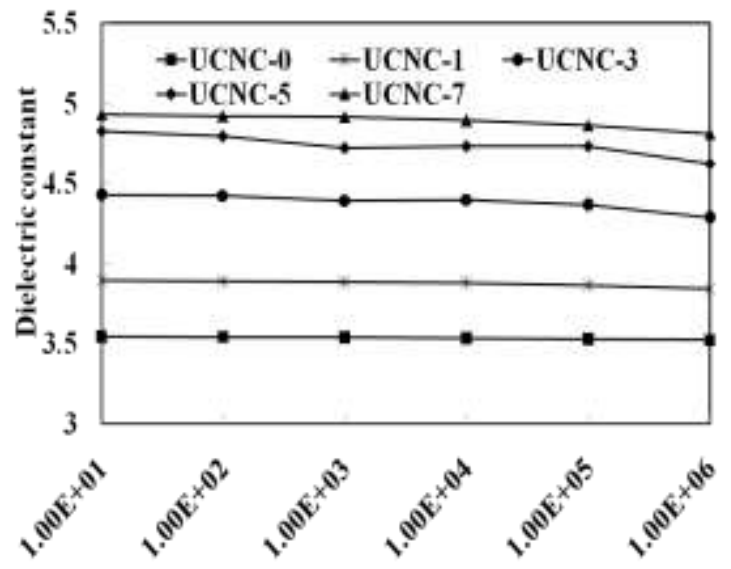

Frequency $(\mathrm{Hz})$

FIGURE 5. Effect of OMMT content on dielectric constant of uncompatibilised EPDM/Silicone rubber nanocomposites at various frequencies

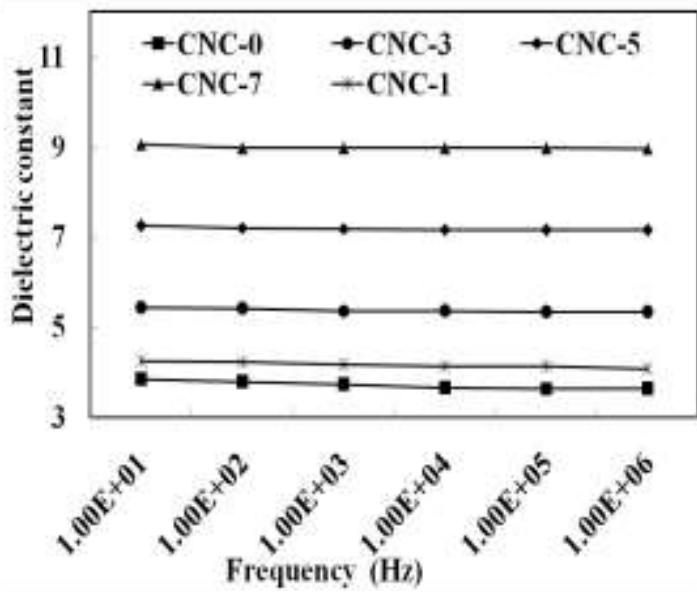

FIGURE 6.Effect of OMMT content on Dielectric constant of compatibilised EPDM/Silicone rubber 


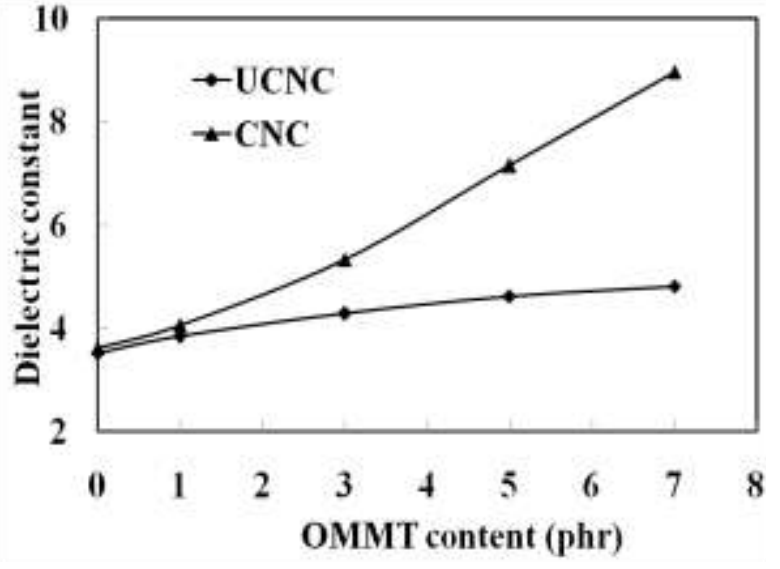

FIGURE 7. Effect of OMMT content on dielectric constant of compatibilised and uncompatibilised EPDM/Silicone rubber nanocomposites at $1 \mathrm{MHz}$

\subsubsection{Surface resistivity}

In FIGURE 8 and 9, the surface resistivity of the uncompatibilised and compatibilised nanocomposites respectively are plotted against OMMT content.

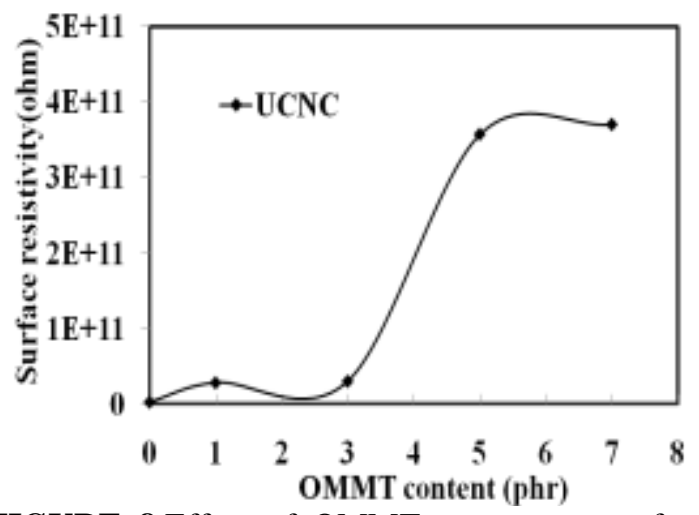

FIGURE 8.Effect of OMMT content on surface resistivity of uncompatibilised EPDM/Silicone rubber nanocomposites

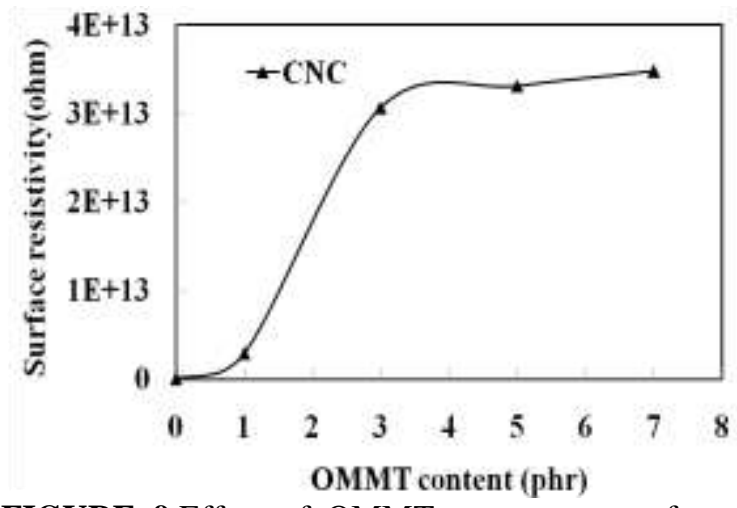

FIGURE 9.Effect of OMMT content on surface resistivity of uncompatibilised EPDM/Silicone rubber nanocomposites
From the FIGURE 8 and 9, it was found that the surface resistivity increased with increasing level of OMMT content. Compatabilised nanocomposites show better resistance than uncompatibilised nanocomposites due to the good interaction of nanofiller with rubber matrix.

\subsubsection{Volume resistivity}

The values of volume resistivity obtained for various nanocomposites are presented in FIGURE 10 and 11. It was found that $5 \mathrm{phr}$ of OMMT was the critical level for volume resisstivity in both compatibilised and uncompatibilised nanocomposites. Compatabilised EPDM/Silicone rubber nanocomposites shows higher values than the uncompatibilised nanocomposites. This indicates that, there is a more interaction between EPDM and silicone rubbers and better dispersion of the nanofiller in the rubber matrix phase.

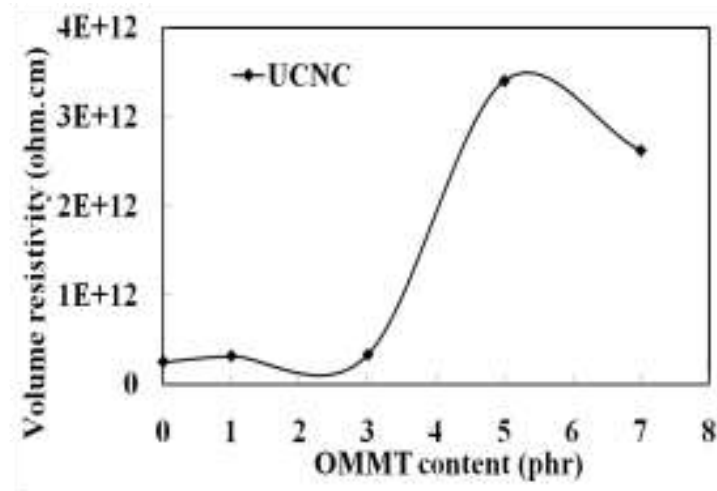

FIGURE 10.Effect of OMMT content on volume resistivity of uncompatibilised EPDM/Silicone rubber nanocomposites

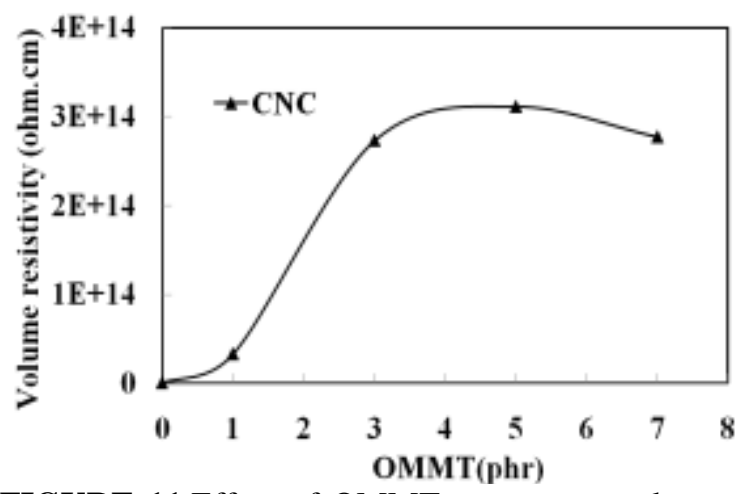

FIGURE 11.Effect of OMMT content on volume resistivity of compatibilised EPDM/Silicone rubber nanocomposites

\subsubsection{Dissipation factor (tan $\square)$}

Dissipation factor $(\tan \delta)$ as a function of frequency in the range of $10-10^{6} \mathrm{~Hz}$ for both un compatibilised and compatibilised nanocomposites and at $1 \mathrm{MHz}$ are shown in FIGURE 12, 13 and 14 
respectively. Dissipation factor increased with increasing frequency. This may be due to the charge mobility at higher frequencies. The dissipation factor of the uncompatibilised nanocomposites was found to be decreased with increasing OMMT content upto the loading of 5 phr. Above 5 phr it shows an increasing trend due to the poor dispersion of filler in the matrix phase.The same trend was observed in the case of compatibilised nanocomposites with comparatively higher values. This revealed better dispersion of OMMT in presence of the compatibiliser.
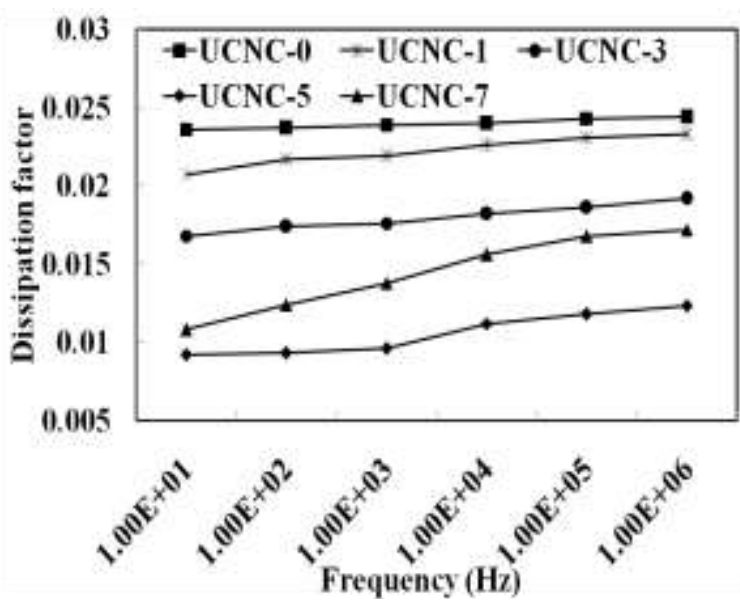

FIGURE 12.Effect of OMMT content on Dissipation factor of uncompatibilised EPDM/Silicone rubber nanocomposites

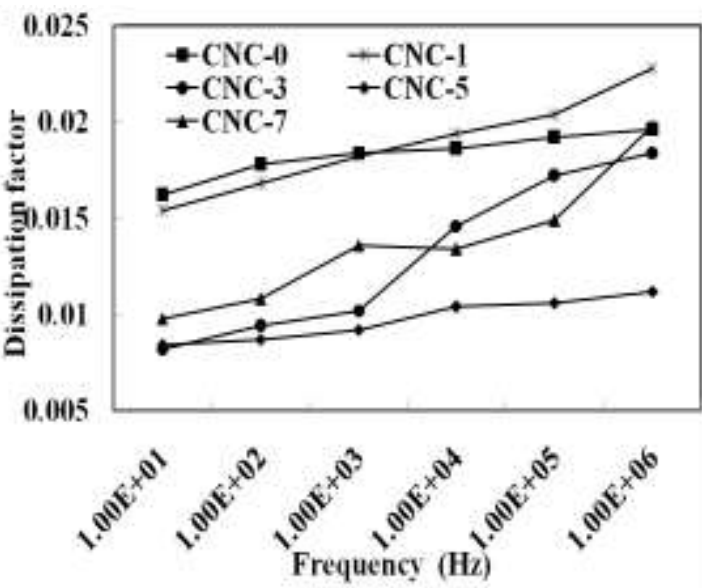

FIGURE 13.Effect of OMMT content on dissipation factor of compatibilised EPDM/Silicone rubber nanocomposites

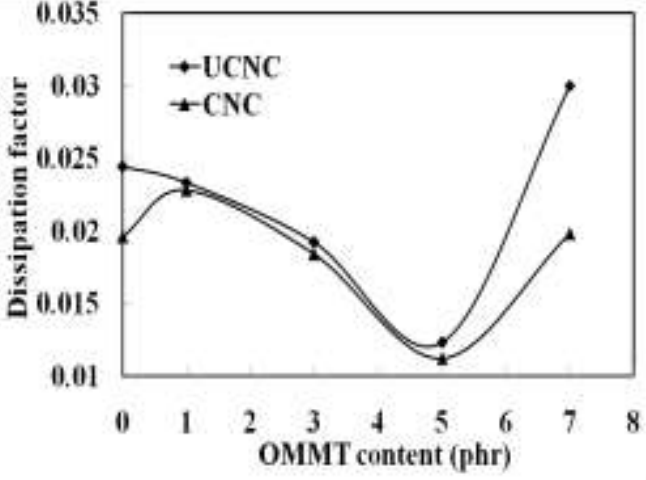

FIGURE 14.Effect of OMMT content on dissipation factor of uncompatibilised and compatibilised EPDM/Silicone rubber nanocomposites at $1 \mathrm{MHz}$

\subsection{Thermogravimetric analysis (TGA)}

Thermal stability of EPDM/Silicone rubber nanocomposites has been investigated by using thermogravimetric analysis (TGA). Degradation behaviour is shown in FIGURE 15 and 16. It can be seen from the TGA thermogram that, both compatibilised and uncompatibilised blends do not undergo any change in the temperature below $200^{\circ} \mathrm{C}$. The thermal stability of uncompatibilised and compatibilised nanocomposites increases with OMMT loading shows its ability to retard the heat diffusion into the rubber matrix.

Also it is clear from the FIGURE 17 that the initial decomposition temperature increases slightly but not much difference between uncompatibilised and compatibilised nanocomposites. The temperature at which 50\% decomposition of nanocomposites occurs has been found to be increased as the phr of OMMT increases (FIGURE 18).

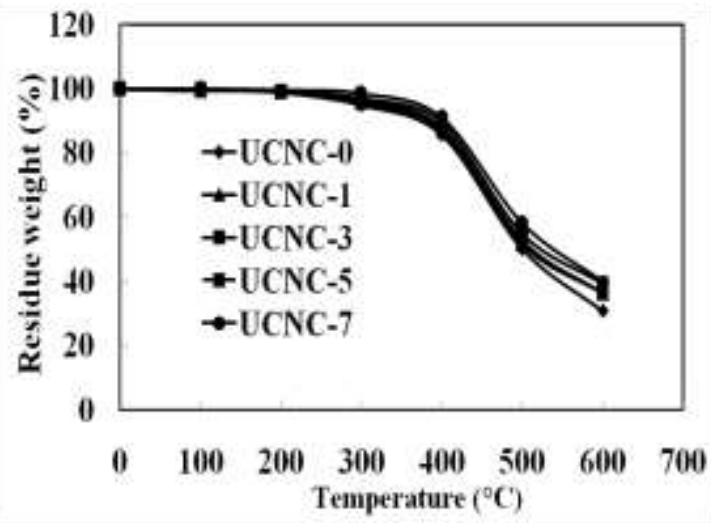

FIGURE 15.TGA curves for uncompatibilised EPDM/Silicone rubber nanocomposites 


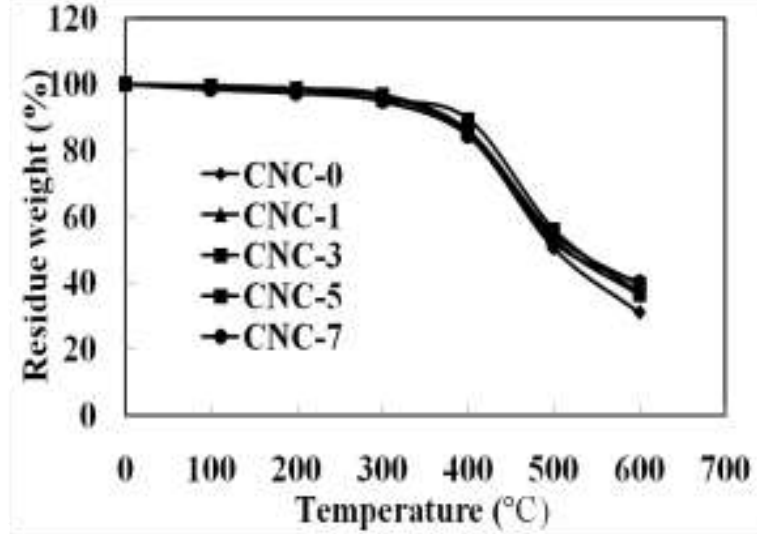

FIGURE 16.TGA curves for compatibilised EPDM/Silicone rubber nanocomposites

$50 \%$ decomposition of compatibilised nanocomposites ocuurs at higher temperature compared to uncompatibilised nano composites. This shows the better interaction in compatibilised nanocomposites and its effects was revealed by mechanical and electrical properties.

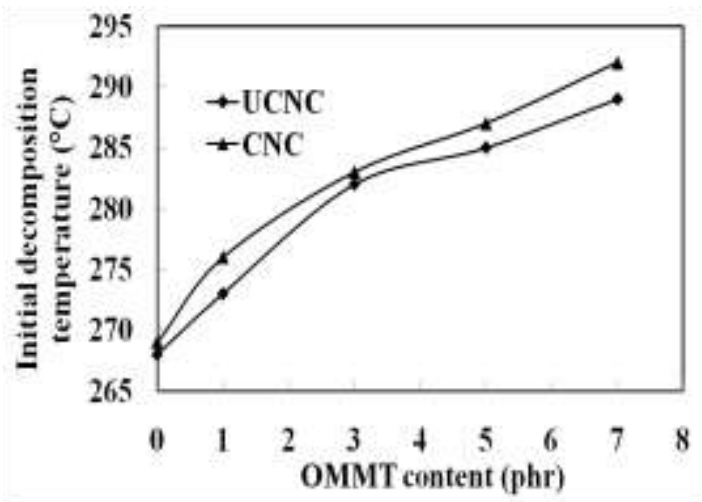

FIGURE 17. Effect of OMMT on initial decomposition temperature of compatibilised and uncompatibilised EPDM/Silicone rubber nanocomposites

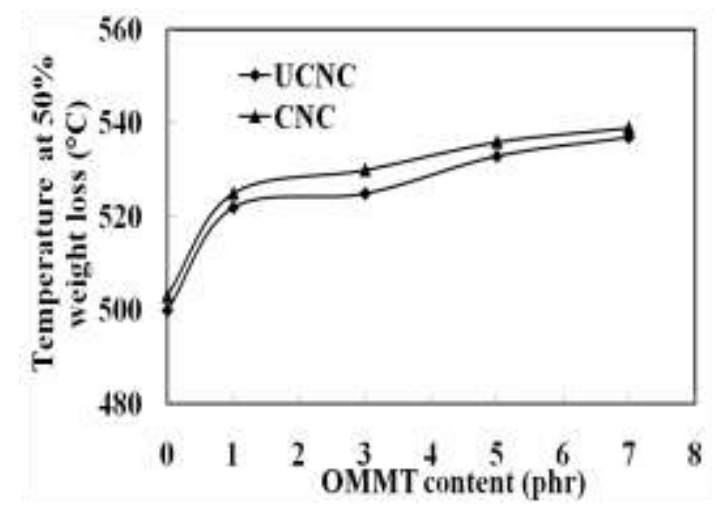

FIGURE 18. Effect of OMMT on $50 \%$ weight loss temperature of compatibilised and uncompatibilised EPDM/Silicone rubber nanocomposites
It can be concluded that, the nanocomposites containing OMMT exhibits higher thermal stability compared to the convensional composites. This improvement attributes the delay in diffusion of volatile decomposition products from the nanocomposite structure.

\subsection{Transmission electron microscopy (TEM)}

HRTEM images of compatibilised OMMT/ EPDM/Silicone nanocomposites at filler loading of $5 \mathrm{phr}$ are shown in FIGURE 19. The bright background in the transmission electron micrograph 19 (b) is the polymer matrix which shows the compatibility achieved in EPDM and silicone blend. It is inferred from the TEM image 19 (a) that OMMT was uniformly dispersed in the EPDM/Silicone matrix as an exfoliated structure.

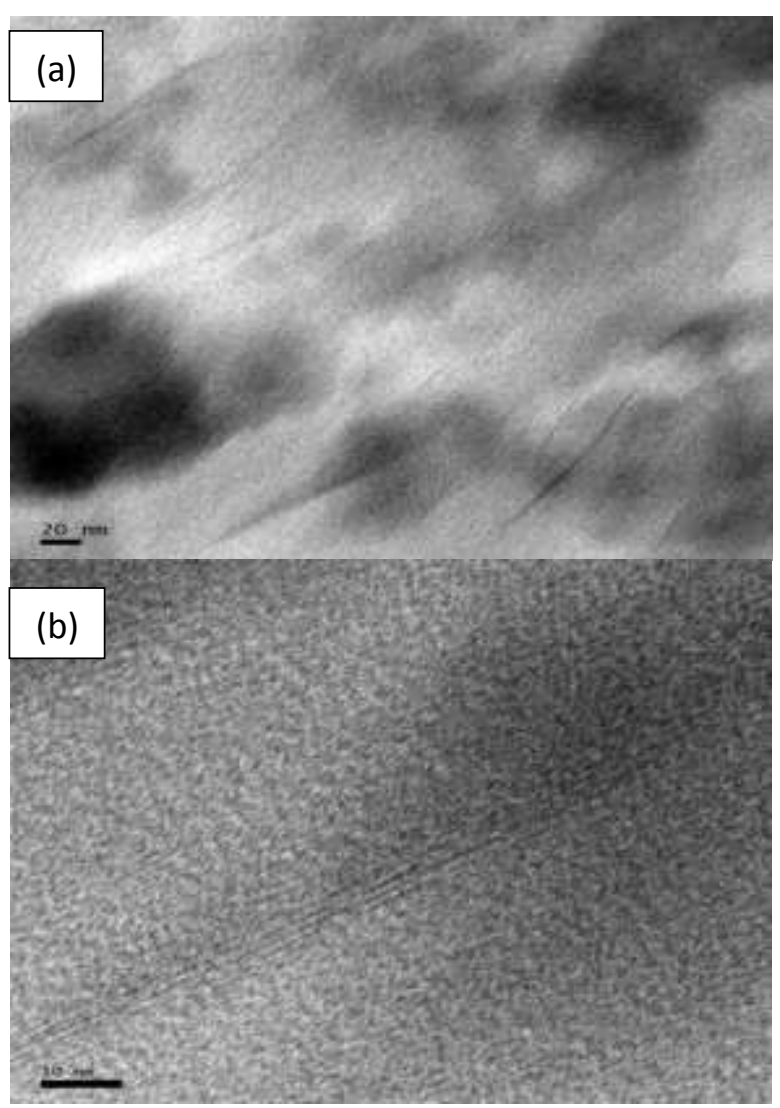

FIGURE 19 (a) and (b). HRTEM images of EPDM/Silicone/OMMT nanocomposite

\section{CONCLUSIONS}

Compatibilised and uncompatibilised EPDM/Silicone nanocomposites were developed with varying proportions of organically modified montmorillonite nanoclay (OMMT). The effect of compatibilisation and the addition of OMMT on mechanical, electrical and thermal properties have been investigated. The results obtained for mechanical properties shows the significant 
improvement in tensile strength, elongation at break and hardness in both compatibilised and uncompatibilised nanocomposites with increasing OMMT content. The maximum values of tensile strength and elongation at break obtained at loading of $5 \mathrm{phr}$ of OMMT. The study of electrical properties reveals that the presence of OMMT in both compatibilised and uncompatibilised nanocomposites offer marked improvement.The increasing trend of dielectric strength and volume resistivity was achieved upto the loading of $5 \mathrm{phr}$ of OMMT. The dissipation factor was decreased in nanocomposites when increasing the loading of OMMT from 0 to $5 \mathrm{phr}$. Thermogravimetric analysis confirm the improvement in thermal stability of nanocomposites with increasing content of OMMT. TEM photographs shows uniformly distributed exfoliated structure of nanocomposite at $5 \mathrm{phr}$ and compatibility of matrices. For

\section{REFERENCES}

[1]. LilianceBokobza, Silicon-Springer, 2009,1, 141-144.

[2]. Sritamakar, Pradip K Maji, Anil K Bhowmick, J. mat. Sci., 2010, 45,64-73.

[3]. Shimpi N.G, Mishra S, J. nanopart ResSpringer, 2009, 12, 2093-2099.

[4]. Cherney E.A, IEEE Transactions on Dielectrics and Electrical Insulation, 2005, 12, 1108-1115.

[5]. Damien M. Marquis, Eric Guillaume and CarineChivas-Joly, Laboratoire national de metrologieetd'essais (LNE) France, 261284.

[6]. Sui G, Zhong W.H, Yang X.P, Yu Y.H, Zhao S.H, Polym. for adv. Tech 2008.

[7]. Johan Andersson, Stanislaw M. GubanskiHenrikHillborg, 2008, 15 ( 5), 1360-1367.

[8]. GrazynaJanowska, AgnieszkakucharskaJastrzabek,

PrzemyslanRybinski, J. thermal analysis calorim, 2011, 103, 1039-1046.

[9]. PradipK.Maji, K. Prasanta, Guchhait, Anil K.Bowmick, J. mat. Sci., 2009, 44, 58615871.

[10]. Alexandre M, Dubois P, Mat. Sci. Eng., 2000, 28, 1-63.

[11]. Da Silva C, Haidar B, Vidal A, Miehebrendle J, Le dred R, Vidal, J. mat. Sci., 2005, 40, 1813 - 1815.

[12]. Sudhakara P, Kannan P, Obireddy K , VaradaRajulu A, Springer, 2011, 2778-2788.

[13]. JunpingZheng, Wei Zhang, Hongyan Li, Jian Li, J. polym Res- Springer, 2011, 18, 2359-2365. compatibilised nanocomposites, better results for mechanical, electrical and thermal properties were obtained compared to that of uncompatibilised nanocomposites. The experimental results show that the compatibilised EPDM/Silicone nanocomposite with $5 \mathrm{phr}$ OMMT can be a better candidate for high voltage electrical insulation due its enhanced mechanical, themal and dielectric characteristics.

\section{ACKNOWLEDGEMENTS}

I wish to express my gratitude to Dr.S.S.M.AbdulMajeed, professor and head, Department of Polymer Technology, B.S. AbdurRahman University for his support in this work

[14]. Onsy I, Dimitry H, Ziri Ibrahim Abdeen, Ismail E.A., Saad A.L.G, J Polym Res Springer, 2010, 17, 801-813.

[15]. June-Ho Lee, W.Y Ji, Proceeding of the 7th international conference on properties and applications of dielectric materials, 2003, June 1-5 Nagoya. 591-594.

[16]. Ehsani M, Borsi H, Gockenbach E, Bakhshandeh G.R, Morshedian J, IEEE Annual report conference on electrical insulation and dielectric phenomena, 2004, 623-626.

[17]. Raja Prabu R, Usa S, Udayakumar K, Abdul Majeed S.S.M, Abdullah Khan M, IEEE Transactions on Dielectrics and Electrical insulation, 2007, 14, 1207-1214.

[18]. Ehsani M, Borsi H, Gockenbach E, Bakhshandeh G.R, Morshedian J, N. Abedi, IEEE International conference on solid dielectrics, Toulouse, France, 2004, 5-9, July. 